\title{
Postural stability at different heights as well as in natural standing position and during tandem stance in female athletes who practice artistic gymnastics
}

\author{
JAROSŁAW OMORCZYK ${ }^{1}$, KRZYSZTOF WRZEŚNIEWSKI ${ }^{2}$, \\ ROBERT STASZKIEWICZ ${ }^{3}$, EWA PUSZCZAŁOWSKA-LIZIS ${ }^{4} *$ \\ ${ }^{1}$ Institute of Sport, Faculty of Physical Education and Sport, University School of Physical Education, Kraków, Poland. \\ 2 Department of Psychology, University of Physical Education, Kraków, Poland. \\ ${ }^{3}$ Department of Biomechanics, Faculty of Physical Education and Sport, University of Physical Education, Kraków, Poland. \\ ${ }^{4}$ Institute of Health Sciences, Medical College, University of Rzeszow, Rzeszów, Poland.
}

\begin{abstract}
Purpose: The aim of this work was the assessment of postural stability at different heights as well as in natural standing position and during tandem stance in female athletes who practice artistic gymnastics. Methods: The study comprised 34 athletes aged 8-12, practicing artistic gymnastics at a sports club „Korona Kraków”. The research tool was CQ-Stab 2P two-platform posturograph. The elevation was achieved using the Light SPL platform. The data were analyzed based on Wilcoxon signed-rank test and Spearman's rank correlation. Results: The height at which the posturograph was set differentiated the path length of the statokinesiogram, both in the natural stance $(p=0.035)$ and tandem stance $(p=0.012)$. When the posturograph was placed on the floor, statistically significantly higher sway area delimited by the COP point $(p<0.001)$, statokinesiogram path length $(p<0.001)$, mean amplitude of COP displacement $(p<0.001)$ and mean frequency of COP displacement $(p=0.048)$ values were recorded in the tandem stance position. On the other hand, when the posturograph was placed on a landing, statistically significantly higher sway area delimited by the COP point $(p<0.001)$, statokinesiogram path length $(p<0.001)$ and mean frequency of COP displacement $(p<0.001)$ values were recorded in the tandem stance position. Conclusions: Increasing height was accompanied by deterioration of stability indices. Postural stability improves with training experience.
\end{abstract}

Key words: natural stance, tandem stance, balance on the floor, balance on the landing

\section{Introduction}

Performing motor tasks in artistic gymnastics requires the development of body control mechanisms that allow for maintaining balance in unnatural motor tasks. A particularly difficult challenge for female athletes practicing this sport discipline is exercising on balance beam [18], [23]. The main difficulty in performing motor tasks on this device is the need to maintain balance in the conditions of a decreasing width of the support area and a decreasing angle of equilibrium in the frontal plane. This requires athletes to make significant adjustments to the balance control process [19]. Balancing on a balance beam that is only $10 \mathrm{~cm}$ wide requires initial mastering the technique of gymnastic movements on the floor [1].

The height of the balance beam has a significant influence on the technique, aesthetics and smoothness of movements. In the conditions of sports competitions, the balance beam is placed at a height of $1.25 \mathrm{~m}$ from the ground [12]. However, while teaching the gymnastic elements, it can be set at different heights. This approach ensures gradual familiarization with the performance of movements at height, and also increases the comfort and safety during the performance of motor tasks.

* Corresponding author: Ewa Puszczałowska-Lizis, Medical College, Institute of Health Sciences, University of Rzeszów, ul. Warzywna 1A, 35-959, Rzeszów, Poland. Phone: +48 882056555, e-mail: ewalizis@poczta.onet.pl

Received: June 9th, 2021

Accepted for publication: October 3rd, 2021 
The results of available studies indicate that practicing artistic gymnastics has a beneficial effect on the course of processes related to balance control [1], [2], [9], [13], [14], [20], [26]. However, the method of these studies took the positioning of the measurement platforms on the floor into account. In this way, the influence of a variable significant for this sport - such as height - was ignored. Test protocols involving balance measurements with the setting of stabilometric platforms at different heights were used only in studies of non-training individuals, mainly to assess the degree of fear of falling [15], [17], [24]. It has been shown that changes in indices of sensorimotor balance control occur in people standing on a platform placed on a landing including an increase in the frequency of corrective reactions. Increased co-contraction of the lower limb muscles was also observed, as well as physiological and psychological responses in response to a fall hazard [6]-[8], [21], [30]. Increase in anxiety and reduced balance specific self-efficacy were typical [5], [16], [31]. Carpenter et al. [5] concluded that older adults used the same stiffening strategy as younger to cope with the increased anxiety and lowered confidence associated with standing on a high surface. In turn, Brown et al. [3] found that age did not influence how anxiety influenced the regulation of postural control.

The aim of this study was the assessment of postural stability at different heights as well in natural standing position and during tandem stance in female athletes who practice artistic gymnastics. The authors wanted to answer whether the positioning of the posturograph on the floor and a $1.25 \mathrm{~m}$ high landing, and the arrangement of the measuring platforms differentiate the values of the body stability indices in female athletes, what the relationships between the synonymous stability indices recorded in natural stance and tandem stance positions are and which of the body stability indices recorded in individual trials show relationships with training experience of female athletes practicing gymnastics.

\section{Materials and methods}

\subsection{Participants}

The study performed in June 2020 comprised 34 athletes aged 8-12, practicing artistic gymnastics at a sports club „Korona Kraków”.

Selection of the research groups was purposive. The inclusion criteria were: performing gymnastics competitively, training experience of 3-6 years, no complaints resulting from injuries to the musculoskeletal system, systematic attendance at classes, twice a week, written informed consent parents/legal guardians to participate in the study.

The average length of the training experience of the surveyed girls was $4.40 \pm 1.00$ years. The obtained data show that the average body mass of the studied athletes was $\bar{x}=28.11 \pm 6.89 \mathrm{~kg}$, the average body height was $\bar{x}=132.40 \pm 11.43 \mathrm{~cm}$, while the mean BMI shaped on the level $15.79 \pm 1.49$.

The study was approved by the Bioethics Committee at the University of Rzeszów, Poland (Approval Ref. No. No. 10/12/2019). All participants, their parents/legal guardians were furnished with detailed information on the aims and methods to be used throughout the study, and gave their written informed consent to participate in the research.

\subsection{Examination protocol}

The research tool was CQ-Stab 2P two-platform posturograph (manufactured by CQ Electronic System). The construction of the posturograph allowed for free arrangement of the platforms. The measurements of stability consisted of four 30 -second tests. The first attempt (NF - natural, floor) was the measurement of the body stability in a natural standing position (natural stance). The platforms were arranged on the floor parallel to each other, were levelled, their surfaces aligned in a single plane. After entering the platform, the subject stood still trying to keep her eyes on the fixation point which was placed 1 meter away. The stance width of the lower limbs and the feet angle were natural, unforced (Fig. 1a). Subsequently, the second test ( $\mathrm{TF}$ - tandem, floor) was conducted while the foot of the dominant lower limb was placed in front of the foot of the non-dominant lower limb (tandem stance). Before measuring the body stability in this position, the plates of the platform were placed one in front of the other (Fig. 1b). The third test (NL - natural, landing) was carried out on the same principle as first test (Fig. 1c), in turn, during the fourth test (TL - tandem, landing), the study participants performed the same principle as the second test (Fig. 1d), except that the posturograph was placed on a $1.25 \mathrm{~m}$ high landing, which simulated the conditions for performing gymnastic exercises on a balance beam, in accordance with the standards adopted by the International Gymnastics Federation [12]. The elevation was achieved using the Light SPL platform (Alspaw Group) with the possibility of height adjustment. For safety reasons 


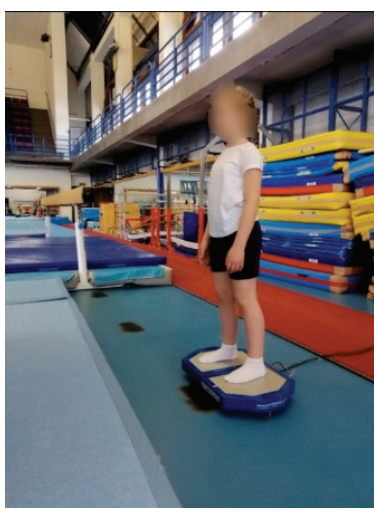

(a)

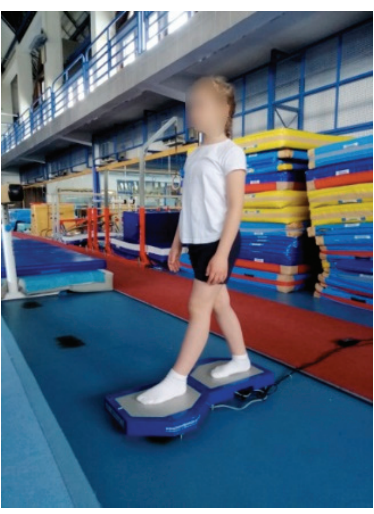

(b)

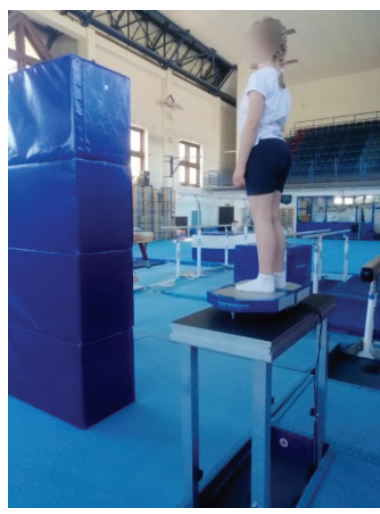

(c)

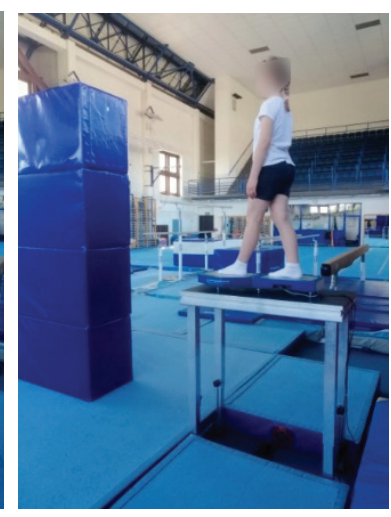

(d)

Fig. 1. The manner of carrying out the measurements of stability: (a) quiet stance on the floor (NF - natural, floor); (b) tandem stance on the floor ( $\mathrm{TF}$ - tandem, floor); (c) quiet stance on the platform $1.25 \mathrm{~m}$ (NL - natural, landing); (d) tandem stance on the platform $1.25 \mathrm{~m}$ (TL - tandem, landing)

Source: own study. The authors obtained the participant's and their parents consent to publish the images

during the measurement, members of the research team were present near the measuring stand, and $20 \mathrm{~cm}$ heigh mattresses were placed around the platform.

In order to preserve the integrity of the research process, all the tests were carried out in the morning, using the same measuring instruments operated by the authors. The measurements were carried out in the gym, in conditions which ensure the isolation of acoustic stimuli that could interfere with postural reflexes during the study. Athletes were wearing gymnastic costumes without shoes. All procedures were carried out in full compliance with the Declaration of Helsinki.

The following indices of stability were analyzed:

- SA $\left[\mathrm{mm}^{2}\right]$ - sway area delimited by the COP point (i.e., the surface area of an irregularly shaped polygon, demarcated by a boundary line connecting up the extreme points of the statokinesiogram);

- SP [mm] - statokinesiogram path length;

- MA [mm] - mean amplitude (radius) of COP displacement;

- MF $[\mathrm{Hz}]$ - mean frequency of COP displacement (i.e., the ratio of the total statokinesiogram's path length (on both axes) to the circumference of the circle whose radius is equal to the average COP displacement calculated per 1 second).

\subsection{Statistical analysis}

The consistency of the values with the normal distribution was verified by means of the Shapiro-Wilk test. The data were analyzed based on Wilcoxon signed-rank test and Spearman's rank correlation. The strength of the correlation was determined on the basis of the adjective scale according to Stanisz [27]: $R_{X Y}=0.0$ variables are not correlated; $0.0<R_{X Y}<0.1$ slim correlation; $0.1 \leq R_{X Y}<0.3$ weak correlation; $0.3 \leq R_{X Y}$ $<0.5$ average correlation; $0.5 \leq R_{X Y}<0.7$ strong correlation; $0.7 \leq R_{X Y}<0.9$ very strong correlation; $0.9 \leq$ $R_{X Y}<1.0$ almost complete correlation.

Results were considered statistically significant if the probability level of the test was lower than the predetermined level $\alpha=0.05$. The Statistica Stat Soft application (version 13.1) was used to process the test results.

\section{Results}

The data collected in Table 1 show statistically significant differences in the values of the path length statokinesiogram indices obtained in the corresponding tests performed under the conditions of placing the posturograph on the floor and on the landing. The aforementioned differences concerned both the tests performed in the natural stance $(p=0.035)$, and the tandem stance $(p=0.012)$ position. The values of the statokinesiogram path length were higher in the tests on the posturograph placed on the landing.

In conditions where the posturograph was on the floor, the feet position differentiated the values of all stability indices. In the tandem stance position, statistically significantly higher values of sway area delimited by the COP point $(p<0.001)$, statokinesiogram path length $(p<0.001)$, mean amplitude of COP displacement $(p<0.001)$ and mean frequency of COP displacement ( $p=0.048$ ) were recorded (Table 1). On the other hand, when the posturograph was placed on a landing, statistically significantly higher sway area 
Table 1. Comparison of the values of stability indices obtained in individual tests

\begin{tabular}{|c|c|c|c|c|c|c|}
\hline \multicolumn{2}{|c|}{ Stability indicator } & $\bar{x} \pm \mathrm{SD}$ & $\mathrm{Me}$ & Max-min & $Z$ & $p$ \\
\hline \multicolumn{7}{|c|}{ Natural stance on the floor - Natural stance on the landing } \\
\hline \multirow{2}{*}{$\mathrm{SA}\left[\mathrm{mm}^{2}\right]$} & $\mathrm{NF}$ & $479.82 \pm 215.29$ & 467.00 & $959.00-183.00$ & \multirow{2}{*}{-1.85} & \multirow{2}{*}{0.064} \\
\hline & NL & $534.50 \pm 286.17$ & 436.50 & $1651.00-230.00$ & & \\
\hline \multirow{2}{*}{$\mathrm{SP}[\mathrm{mm}]$} & $\mathrm{NF}$ & $467.20 \pm 72.91$ & 461.50 & $617.00-333.00$ & \multirow{2}{*}{-2.11} & \multirow{2}{*}{$0.035^{*}$} \\
\hline & $\mathrm{NL}$ & $482.32 \pm 70.25$ & 476.50 & $627.00-365.00$ & & \\
\hline \multirow{2}{*}{$\mathrm{MA}[\mathrm{mm}]$} & $\mathrm{NF}$ & $3.04 \pm 1.26$ & 2.80 & $6.00-1.40$ & \multirow{2}{*}{-1.94} & \multirow{2}{*}{0.052} \\
\hline & NL & $3.38 \pm 1.62$ & 2.90 & $8.70-1.60$ & & \\
\hline \multirow{2}{*}{$\mathrm{MF}[\mathrm{Hz}]$} & $\mathrm{NF}$ & $0.94 \pm .35$ & 0.86 & $1.72-0.39$ & \multirow{2}{*}{-1.80} & \multirow{2}{*}{0.071} \\
\hline & NL & $0.91 \pm 0.41$ & 0.81 & $1.72-0.35$ & & \\
\hline \multicolumn{7}{|c|}{ Tandem stance on the floor - Tandem stance on the landing } \\
\hline \multirow{2}{*}{$\mathrm{SA}\left[\mathrm{mm}^{2}\right]$} & $\mathrm{TF}$ & $1395.85 \pm 1373.93$ & 960.50 & $8439.00-376.00$ & \multirow{2}{*}{-1.27} & \multirow{2}{*}{0.203} \\
\hline & TL & $1560.41 \pm 1196.11$ & 1314.50 & $6828.00-380.00$ & & \\
\hline \multirow{2}{*}{$\mathrm{SP}[\mathrm{mm}]$} & TF & $739.82 \pm 166.09$ & 724.50 & $1406.00-500.00$ & \multirow{2}{*}{-2.52} & \multirow{2}{*}{$0.012 *$} \\
\hline & TL & $799.79 \pm 190.83$ & 784.50 & $1426.00-488.00$ & & \\
\hline \multirow{2}{*}{ MA $[\mathrm{mm}]$} & $\mathrm{TF}$ & $5.33 \pm 2.12$ & 4.80 & $12.10-2.20$ & \multirow{2}{*}{-1.65} & \multirow{2}{*}{0.099} \\
\hline & TL & $5.95 \pm 2.44$ & 5.55 & $14.20-2.30$ & & \\
\hline \multirow{2}{*}{$\mathrm{MF}[\mathrm{Hz}]$} & $\mathrm{TF}$ & $0.80 \pm 0.23$ & 0.74 & $1.40-0.45$ & \multirow{2}{*}{-0.97} & \multirow{2}{*}{0.334} \\
\hline & TL & $0.78 \pm 0.24$ & 0.75 & $1.67-0.47$ & & \\
\hline & & ral stance on the flo & Tandem s & e on the floor & & \\
\hline $\mathrm{SA}\left[\mathrm{mm}^{2}\right]$ & $\mathrm{NF}$ & $479.82 \pm 215.29$ & 467.00 & $959.00-183.00$ & -495 & $<0001 *$ \\
\hline & $\mathrm{TF}$ & $1395.85 \pm 1373.93$ & 960.50 & $8439.00-376.00$ & -4.95 & $<0.001$ \\
\hline $\mathrm{SP}[\mathrm{mm}]$ & $\mathrm{NF}$ & $467.21 \pm 72.91$ & 461.50 & $617.00-333.00$ & -509 & $<0001 *$ \\
\hline $\mathrm{SP}$ [mm] & $\mathrm{TF}$ & $739.82 \pm 166.09$ & 724.50 & $1406.00-500.00$ & -5.09 & $<0.001^{*}$ \\
\hline A & NF & $3.04 \pm 1.26$ & 2.80 & $6.00-1.40$ & $4=0$ & $<0001 *$ \\
\hline $\mathrm{MA}[\mathrm{mm}]$ & TF & $5.32 \pm 2.12$ & 4.80 & $12.10-2.20$ & -4.58 & $<0.001^{*}$ \\
\hline $\mathrm{MF}[\mathrm{Hz}]$ & NF & $0.80 \pm 0.04$ & 0.86 & $1.72-0.39$ & & $0048 *$ \\
\hline$[\mathrm{MIF}$ [HZ] & $\mathrm{TF}$ & $0.94 \pm 0.06$ & 0.74 & $1.40-0.45$ & -1.91 & $0.048^{\circ}$ \\
\hline & & stance on the landi & Tandem s & e on the landing & & \\
\hline $\mathrm{SA}\left[\mathrm{mm}^{2}\right]$ & NL & $534.50 \pm 49.08$ & 436.50 & $1651.00-230.00$ & & $<0001 *$ \\
\hline$S A[11111]$ & TL & $1560.41 \pm 205.13$ & 1314.50 & $6828.00-380.00$ & & -0.001 \\
\hline SP [mm] & NL & $482.32 \pm 70.25$ & 476.50 & $627.00-365.00$ & & $<0001 *$ \\
\hline $\mathrm{SP}$ [mm] & TL & $799.79 \pm 190.83$ & 784.50 & $1426.00-488.00$ & -5.01 & $<0.001^{\circ}$ \\
\hline $\mathrm{MA}[\mathrm{mm}]$ & NL & $3.38 \pm 1.62$ & 2.90 & $8.70-1.60$ & -439 & $<0001 *$ \\
\hline MA [mm] & TL & $5.95 \pm 2.44$ & 5.55 & $14.20-2.30$ & -4.39 & $<0.001^{*}$ \\
\hline $\mathrm{MF}[\mathrm{Hz}$ & NL & $0.91 \pm 0.041$ & 0.81 & $1.72-0.35$ & -178 & 0075 \\
\hline 1011 [112] & TL & $0.78 \pm 0.24$ & 0.75 & $1.67-0.47$ & -1.10 & 0.073 \\
\hline
\end{tabular}

SA - sway area delimited by the COP point; SP - statokinesiogram path length; MA - mean amplitude of COP displacement; $\mathrm{MF}$ - mean frequency of COP displacement; NF - natural, floor; TF - tandem, floor; NL - natural, landing; TL - tandem, landing; $\bar{x}$ - arithmetical mean value; SD - standard deviation; max - maximum value; min - minimum value; Me - median; $Z$ - value of the Wilcoxon signed-rank test statistic; $p$ - probability value.

$* p<0.05$.

delimited by the COP point $(p<0.001)$, statokinesiogram path length $(p<0.001)$ and mean frequency of COP displacement $(p<0.001)$ values were recorded in the tandem stance position (Table 1).

Statistically significant strong and very strong relationships were noted between the values of stability indices recorded during the tests on the floor and landing. In the case of the natural stance position, the aforementioned relationships concerned the values of indices defining sway area delimited by the COP point $(R=0.61 ; p<0.001)$, statokinesiogram path length $(R=0.86 ; p<0.001)$, mean amplitude of COP dis- placement $(R=0.60 ; p<0.001)$ and mean frequency of COP displacement $(R=0.70 ; p<0.001)$. On the other hand, in the tandem stance, statistically significant correlations concerned the values of the following indices: statokinesiogram path length $(R=0.67$; $p<0.001)$ and mean frequency of COP displacement $(R=0.50 ; p=0.003)$.

There were no statistically significant relationships between the unanimous stability indices recorded in the natural stance and tandem stance tests, both in the case of placing the posturograph on the floor and on the landing (Table 2). 
Table 2. Relationships between synonymous stability indices recorded during trials in natural stance and tandem stance positions

\begin{tabular}{|l|c|c|}
\hline \multicolumn{1}{|c|}{ Pair of variables } & $R$ & $p$ \\
\hline SA NF \& SA NL & 0.61 & $<0.001^{*}$ \\
\hline SP NF \& SP NL & 0.86 & $<0.001^{*}$ \\
\hline MA NF \& MA NL & 0.60 & $<0.001^{*}$ \\
\hline MF NF \& MF NL & 0.70 & $<0.001^{*}$ \\
\hline SA TF \& SA TL & 0.34 & 0.052 \\
\hline SP TF \& SP TL & 0.67 & $<0.001^{*}$ \\
\hline MA TF \& MA TL & 0.50 & $0.003^{*}$ \\
\hline MF TF \& MF TL & 0.03 & 0.845 \\
\hline SA NF \& SA TF & 0.27 & 0.126 \\
\hline SP NF \& SP TF & 0.15 & 0.200 \\
\hline MA NF \& MA TF & 0.23 & 0.186 \\
\hline MF NF \& MF TF & 0.26 & 0.143 \\
\hline SA NL \& SA TL & 0.26 & 0.146 \\
\hline SP NL \& SP TL & 0.29 & 0.099 \\
\hline MA NL \& MA TL & 0.23 & 0.193 \\
\hline MF NL \& MF TL & 0.30 & 0.086 \\
\hline
\end{tabular}

SA - sway area delimited by the COP point; SP statokinesiogram path length; MA - mean amplitude of COP displacement; MF - mean frequency of COP displacement; NF - natural, floor; TF - tandem, floor; NL - natural, landing; TL - tandem, landing; $R$ - Spearman's rank correlation coefficient; $p$ - probability value.

$* p<0.05$.

The training experience negatively correlated with the statokinesiogram path length recorded on the floor $(R=-0.65 ; p<0.001)$ and landing $(R=-0.71 ; p<$ $0.001)$.

Table 3. Relationships of body stability indices with the age and training experience of female athletes practicing artistic gymnastics

\begin{tabular}{|c|c|c|}
\hline Pair of variables & $R$ & $p$ \\
\hline Training experience \& SP NF & -0.65 & $<0.001^{*}$ \\
\hline Training experience \& SP NL & -0.71 & $<0.001^{*}$ \\
\hline
\end{tabular}

SP - statokinesiogram path length; MF - mean frequency of COP displacement; $\mathrm{NF}$ - natural, floor; $\mathrm{TF}$ - tandem, floor; $\mathrm{NL}$ - natural, landing; TL - tandem, landing; $R$ - Spearman's rank correlation coefficient; $p$ - probability value.

$* p<0.05$.

\section{Discussion}

In our material, the height at which the posturograph was set differentiated the statokinesiogram path length. This path was longer during the tests performed on the $1.25 \mathrm{~m}$ high landing. Not many studies are available in the literature assessing postural stabil- ity at height. Few studies available include the works of Brown et al. [3], Carpenter et al. [5] and Hauck et al. [16], in which the stiffening strategy was observed during the research on the stability of the body at height. The study by Simeonov and Hsiao [25], provided interesting data, as the factor "height of the body position" influenced the increase in the velocity of the center of pressure displacement of the feet in male construction workers.

The training process of artistic gymnastics athletes is conducive to the optimization of postural control [13]. Already at the stage of selecting for this sport discipline, candidates must demonstrate such predispositions as strength, flexibility and motor coordination [28]. These features may influence the postural control indices. Contrary to non-training individuals, gymnasts have the opportunity to repeatedly perform motor tasks that familiarize them with height. These situations take place not only in the conditions of sports training, but also during social exposures, especially control tests and sports competitions.

In our study, placing the platforms one in front of the other and taking measurements in the tandem stance position resulted in the deterioration of postural stability compared to the test in the natural stance position, both during measurements on the floor and on the landing. The difficulties in performing stability tests in the tandem stance position were evidenced by high values of standard deviations of individual stability indices. It certainly resulted from narrowing of the support plane. Greater variability of stability indices may be dictated by a more complex course of regulation processes that minimize deviations from the assumed equilibrium state. Nam et al. [22] noted that the compensation strategies were triggered as a reaction to the narrowing of the support plane. According to the authors, the activation time and the type of contraction of core muscles are of key importance, a ipsilateral erector spinae muscle is delayed but contralateral internal oblique abdominis are activated anticipatively. It is worth emphasizing here that the measurements carried out in a standing position on feet placed in parallel seem to characterize a general and special balance. In turn, tests in the tandem stance position are used to assess the so-called the special balance that athletes must maintain during gymnastic exercises and sports competitions. Therefore, the assessment of the balance with such a feet setting may have practical implications, both at the stage of sport selection (assessment of predispositions) and during the implementation of sports training.

We noted relationships of synonymous indices defining sway area delimited by the COP point, statoki- 
nesiogram path length, mean amplitude of COP displacement, and mean frequency of COP displacement - in the natural stance position, and correlations statokinesiogram path length and mean frequency of COP displacement - in the tandem stance position. Their positive direction indicates that the increase in height is accompanied by a deterioration of the abovementioned stability indices. On the other hand, the values of the synonymous stability indices recorded in the trials at the same height did not show any mutual relations. The obtained results lead to re-emphasizing the importance of training gymnasts at different heights. There are no publications in the literature that investigate the postural stability at various heights in athletes, especially in those practicing gymnastics, hence it is difficult to relate our results to the studies of other authors. As part of the discussion, the results of Aleksić-Veljković et al. [1], who studied 49 female gymnasts, divided into two age groups $(9.00 \pm 1.10$ years, and $12.10 \pm 0.60$ years), using Balance Error Scoring System, composed of measurements postural stability in six stance conditions on the floor: double-leg, single leg, and tandem stances on both legs, on the firm and foam surface, can be set forth. The authors pointed out that to achieve top results in the women's artistic gymnastics it is necessary to achieve good results on the balance beam and monitoring of balance ability for future success. The reduced support surface, among other capabilities, requires a high level of balance. According to Vuillerme et al. [29], this quite obvious methodological guideline is justified in the dynamic models of information flows during sensorimotor operations. This process may be of particular importance in gymnastics training, as it can switch other sensory systems more efficiently.

Our study shows that statokinesiogram path length recorded on the floor and landing are related to the training experience. These results indicate that gymnastic training improves the mechanisms controlling balance. It appears that fitness and coordination exercises performed in gymnastic training could enhance the level of postural stability. According to Bučar Pajek et al. [4] and Krištofič et al. [19], gymnastics requires a great diversity of movements: transition from dynamic and static elements and vice versa, frequent changes of the body position in space.

It would be beneficial to supplement our results with data based on psychological tests. Some studies indicate that the awareness of the risk of falling and suffering an injury during training consisting in performing motor tasks on devices placed above the ground may intensify the level of anxiety [10], [11]. Such an emotional reaction may trigger the so-called mental blockades affecting the body control process, lowering the quality and disrupting the smoothness of the performed gymnastic elements. It is also worth adding that situations perceived as dangerous to health become a reason for athletes to avoid or refuse to perform physical tasks, aversion to some gymnastic competitions, and even to end their sports career. This may additionally arouse fear of failure during sports competitions, unfavorable reaction of the audience or the trainers [11]. Therefore, the present study aimed at assessing the impact of anxiety on the stability indices would allow for the analysis of the impact of the feeling of being in danger during exercises at height on the ability to maintain balance in a standing position. Such a procedure may complement the knowledge about the directions of selection of the type of exercises and training loads in order to optimize the training process of female athletes practicing artistic gymnastics.

In conclusion, it should be emphasized that our study is pioneering when it comes to measuring postural stability at different heights in athletes. The obtained results are a contribution to further scientific research in order to more accurately review the observed trends. In order to achieve this goal, research on postural stability and its variability due to sports training should be continued. We are convinced that every report regarding the issues undertaken at this paper is a valuable addition to scarce publications on the subject.

\section{Study limitations}

This design has no control group (non-athletes), which might well be regarded as a study limitation. In addition, there is a limitation of not controlling a potential effect of order because the postural stability was not tested in a randomized but fixed order. Therefore, the obtained data may be the result of the so-called „first trial" effect, which takes place when the subject knows the sequence of trials. In this situation, the difference in postural control between each trials may result from changes in arousal levels. Knowledge of the test procedure, or the experience gained from the successful execution of a given test, may influence the perception of subsequent tests as more or less threatening with the loss of balance compared to the previous one.

\section{Conclusions}

Positioning of the posturograph on the landing causes elongation statokinesiogram path length. Placing the platforms one in front of the other affects the deterioration the postural stability in relation to the 
test in the natural stance position, both during measurements on the floor and on the landing.

There are relationships of synonymous indices defining sway area delimited by the COP point, statokinesiogram path length, mean amplitude of COP displacement, and mean frequency of COP displacement - in the natural stance position and correlations of statokinesiogram path length and mean frequency of COP displacement - in tandem stance position. The values of the synonymous stability indices recorded in the trials at the same height do not show mutual relations.

The statokinesiogram path length recorded on the floor and landing are related to the training experience.

\section{Funding}

This study was supported in part by the by the University School of Physical Education in Kraków, (Poland). Project No. 215/BS/IS/2019.

\section{Acknowledgements}

We would like to thank coach Jakub Tyrpa for taking care of the athletes during the examinations.

\section{Competing interests}

The authors declares that they have no competing interests.

\section{References}

[1] Aleksić-Veljković A., Madić D., VeličKović S., HerodeK K., POPOVIĆ B., Balance in young gymnasts: age-group differences, Facta Univ. Se Phys. Educ. Sport, 2014, 12 (3), 289-296.

[2] Arnista P., BiegajŁo M., Mastalerz A., NiźNikowski T., Effects of surface type on balance control strategies in handstand, Pol. J. Sport Tourism, 2020, 27 (4), 9-12.

[3] Brown L.A., POLYCH M.A., DoAn J.B., The effect of anxiety on the regulation of upright standing among younger and older adults, Gait Posture, 2006, 24 (4), 397-405.

[4] BuČar PAJEK M., ČUK I., KovaČ M., JAKŠE B., Implementation of the gymnastics curriculum in: the third cycle of basic school in Slovenia, Sci. Gymnast. J., 2010, 2 (3), 15-17.

[5] Carpenter M.G., Adkin A.L., Brawley L.R., Frank J.S., Postural, physiological and psychological reactions to challenging balance: does age make a difference?, Age Ageing, 2006, 35 (3), 298-303.

[6] Carpenter M.G., Frank J.S., Silcher C.P., Surface height effects on postural control: a hypothesis for a stiffness strategy for stance, J. Vestib. Res., 1999, 9 (4), 277-286.

[7] Carpenter M.G., Frank J.S., Silcher C.P., Peysar G.W., The influence of postural threat on the control of upright stance, Exp. Brain Res., 2001, 138 (2), 210-218.
[8] Cleworth T.W., Horslen B.C., CARPenter M.G., Influence of real and virtual heights on standing balance, Gait Posture, 2012, 36 (2), 172-176.

[9] Croix G., Chollet D., ThouvarecQ R., Effect of expertise level on the perceptual characteristics of gymnasts, J. Strength Cond. Res., 2010, 24 (6), 1458-1463.

[10] De Pero R., Minganti C., Pesce C., Capranica L., PIACENTINI M.F., The relationships between pre-competition anxiety, self-efficacy, and fear of injury in elite Team Gym athletes, Kinesiology, 2013, 45 (1), 63-72.

[11] Duarte L.H., Carbinatto M.V., Nunomura M., Artistic gymnastics and fear: reflections on its causes, Sci. Gymn. J., 2015, 7 (3), 7-21.

[12] FIG Apparatus Norms Parts I-III. Fédération Internationale de Gymnastique, Lausanne 2019.

[13] Garcia C., Barela J.A., Viana A.R., Barela A.M.F., Influence of gymnastics training on the development of postural control, Neurosci. Lett., 2011, 492 (1), 29-32.

[14] Gautier G., Marin L., Leroy D., ThouvarecQ R., Dynamics of expertise level: coordination in handstand, Hum. Mov. Sci., 2009, 28 (1), 129-140.

[15] Gusi N., Carmelo Adsuar J., Corzo H., Del Pozo-Cruz B., Olivares P.R., PARRACA J.A., Balance training reduces fear of falling and improves dynamic balance and isometric strength in institutionalised older people: a randomised trial, J. Physioter., 2012, 58 (2), 97-104.

[16] HaUCK L.J., CARPENTER M.G., FranK J.S., Task-specific measures of balance efficacy, anxiety, and stability and their relationship to clinical balance performance, Gait Posture, 2008, 27 (4), 676-682.

[17] Jung D., Fear of Falling in Older Adults: Comprehensive Review, Asian Nurs. Res., 2008, 2 (4), 214-222.

[18] KALINSKi S.D., BoŽANIĆ A., ATIKOVIĆ A., Influence of dance elements on balance beam results, Sci. Gymn. J., 2011, 3 (2), $39-45$.

[19] KRIŠTOFIČ J., MALÝ T., ZAHÁLKA Z., The effect of intervention balance program on postural stability, Sci. Gymn. J., 2018, 10 (1), 17-27.

[20] Mellos V., Dallas G., Kirialanis P., Fiorilli G., D CAGNo A., Comparison between physical conditioning status and improvement in artistic gymnasts and non-athletes peers, Sci. Gymn. J., 2014, 6 (1), 33-43.

[21] Muddle T.W.D., Fukuda D.H., Wang R., Riffe J.J., Church D.D., BeYer K.S., HofFMAn J.R., Stout J.R., Effects of a 10-week introductory judo course on postural control during a bilateral reactionary gripping task, Motor Control, 2017, 21 (4), 373-389.

[22] NAm HS., KIM J.H., LIM Y.J., The effect of the base of support on anticipatory postural adjustment and postural stability, J. Kor. Phys. Ther., 2017, 29 (3), 135-141.

[23] Ротор V., Timnea O.C., Analysis of biomechanical characteristics of acrobatic elements on balance beam, IJERMT, 2017, 6 (1), 34-41.

[24] Reelick M.F., van Iersel M.B., Kessels R.P.C., Olde RiKKERT M.G.M., The influence of fear of falling on gait and balance in older people, Age Ageing, 2009, 38 (4), 435-440.

[25] Simeonov P., Hsiao H., Height, surface firmness, and visual reference effects on balance control, Inj. Prev., 2001, 7 (11), $50-53$.

[26] Sobera M., Serafin R., RutKowsKa-Kucharska A., Stabilometric profile of handstand technique in male gymnasts, Acta Bioeng. Biomech., 2019, 21 (1), 63-71. 
[27] StAnisz A., An affordable statistics course based on the STATISTICA PL program based on examples from medicine, Stat. Soft. Poland, Kraków 2007.

[28] VeličKović S., Aleksić-Veljković A., HerodeK K., Reliability of coordination tests applied in selection process in artistic gymnastics, Facta Univ. Ser Phys. Educ. Sport, 2013, 11 (3), $325-335$.

[29] Vuillerme N., Danion F., Marin L., Boyadjian A., Prieur J.M., Weise I., Nougier V., The effect of expertise in gymnastics on postural control, Neurosci. Lett., 2001, 303 (2), $83-86$.

[30] Zaback M., Adkin A.L., CARPenter M.G., Adaptation of emotional state and standing balance parameters following repeated exposure to height-induced postural threat, Sci. Rep., 2019, 9 (1), 12449.

[31] Zaback M., Cleworth T.W., Carpenter M.G., AdKIn A.L., Personality traits and individual differences predict threat-induced changes in postural control, Hum. Mov. Sci., 2015, 40, 393-409. 